\title{
Review on powder-based electron beam additive manufacturing technology
}

\author{
Xibing Gong ${ }^{1}$, Ted Anderson ${ }^{2}$, and Kevin Chou ${ }^{1, *}$ \\ 1 Mechanical Engineering Department, The University of Alabama, Tuscaloosa, AL 35487, USA \\ 2 Advanced Manufacturing Team, Marshall Space Flight Center, Huntsville, AL 35811, USA
}

Received 13 January 2014 / Accepted 1 March 2014 / Published online 21 April 2014

\begin{abstract}
This paper presents a thorough literature review of the powder-based electron beam additive manufacturing (EBAM) technology. EBAM, a relatively new additive manufacturing (AM) process, can produce full-density metallic parts directly from the electronic data of the designed part geometry. EBAM has gained broad attentions from different industries such as aerospace and biomedical, with great potential in a variety of applications. The paper first introduces the general aspects of EBAM. The unique characteristics, advantages and challenges of EBAM are then presented. Moreover, the hub of this paper includes extensive discussions of microstructures, mechanical properties, geometric attributes, which impact the application ranges of EBAM parts, with focus on commonly used titanium alloys (in particular, Ti-6Al-4V). In the end, modeling efforts and process metrology of the EBAM process are discussed as well.
\end{abstract}

Key words: Electron beam additive manufacturing (EBAM), Geometric attributes, Mechanical properties, Microstructures, Metallic powder, Process modeling, Process metrology.

\section{Introduction}

Additive manufacturing (AM), also known by various terms, e.g., direct digital manufacturing, based on "layer-bylayer" fabrications is an emerging technology, by which physical solid parts are made directly from electronic data, generally files from computer-aided design (CAD) software. This group of technologies offers many design and manufacturing advantages such as short lead time, complex geometry capability, and tooling free. Electron beam additive manufacturing (EBAM) is a relatively new AM technology [1]. Similar to electron-beam welding, EBAM utilizes a high-energy electron beam, as a moving heat source, to melt and fuse, by rapid self-cooling, metal powder and produce parts in a layer-building fashion. Moreover, EBAM is one of a few AM technologies capable of making full-density functional metallic parts, drastically extending AM applications. In particular, the ability of direct fabrications of metallic parts can significantly accelerate product designs and developments in a wide variety of metallic-part applications, especially for complex components, e.g., fine network structures, internal cavities and channels, which are difficult to make by conventional manufacturing means $[1,2]$.

EBAM machines were first commercialized, around 1997, by Arcam AB Corporation in Sweden. Because EBAM has

\footnotetext{
*e-mail: kchou@eng.ua.edu
}

many unique characteristics such as high energy efficiency, high scan speed, and moderate operation cost, the technology has attracted, in recent years, increased interests from different industries. The use of an electron beam offers extensive features such as higher build rates due to increased penetration depths and rapid scanning speeds. Since then, many research groups have been studying the EBAM technology from different aspects and for various applications. Despite the potential benefits over conventional manufacturing technologies, EBAM still has a few process deficiencies, such as process stability, part defects and quality variations [3], etc. As EBAM technology is relatively new, there have not been detailed reviews. The objective of this paper is to offer a survey of various investigations into EBAM, especially for the study of the titanium (Ti) alloy parts, along with the EBAM part microstructures and associated mechanical properties. In addition, modeling and simulation of the EBAM process, though rare, for process understanding and advancements are also discussed.

\section{EBAM details}

\section{Process principle}

A conceptual schematic of an EBAM machine is shown in Figure 1 [2]. The principle is very similar to that of a scanning 


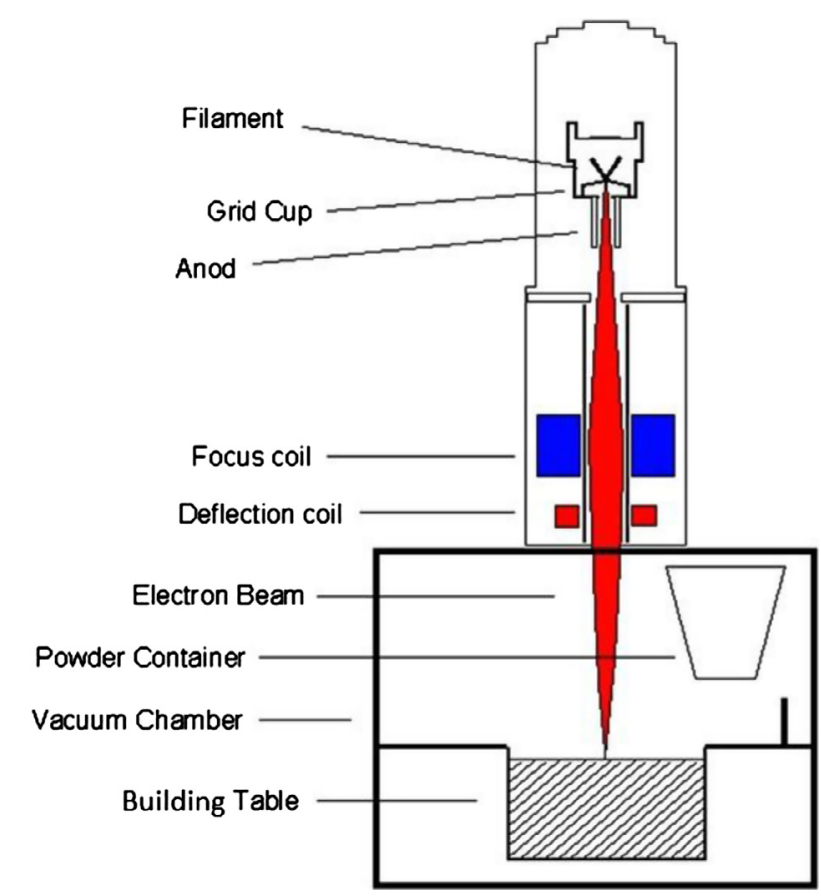

Figure 1. Schematic drawing of an Arcam EBAM machine [2].

electron microscope. A heated tungsten filament, in the upper column, emits electrons which are collimated and accelerated to a kinetic energy of about $60 \mathrm{keV}$. The electron beam is controlled by two magnetic coils, which are housed in the lower column. The first one is a magnetic lens which focuses the beam to the desired diameter, and the second one deflects the focused beam to the desired point on a build platform. The electron-beam gun itself is fixed, no moving mechanical parts involved in beam deflections. The beam current is controlled in the range $1-50 \mathrm{~mA}$ and the beam diameter can be focused down to about $0.1 \mathrm{~mm}$. In the chamber of the middle part of the machine, fine metal powder, on the order of $10-100 \mu \mathrm{m}$, is supplied from two hoppers and forms a thin layer by a raking mechanism before each layer build. The typical layer thickness is in the range $0.05-0.2 \mathrm{~mm}$. The computer-controlled electron beam scans over the powder layer in a predefined pattern and consolidates the desired areas into solid and dense metals. The beam has to first scan at a high speed (order of $10 \mathrm{~m} / \mathrm{s}$ ) in multiple passes to preheat powder to a sintered state, while a beam scan on the order of $\sim 0.5 \mathrm{~m} / \mathrm{s}$ is used during the melting cycle. Then, a new powder layer is laid on top and the scanning process is repeated until all layers are completed.

The entire process takes place under a high vacuum. The typical pressure of residual gases in an EBAM machine is $10^{-1} \mathrm{~Pa}$ in the vacuum chamber and $10^{-3} \mathrm{~Pa}$ in the electron gun [2]. During the melting process, a low pressure of inert helium gas $\left(10^{-1} \mathrm{~Pa}\right)$ is added to the vacuum chamber to avoid build-up of electrical charges in powder. When all layers have been completed, the built part is allowed to cool inside the process chamber, which is then filled up with helium as to assist cooling. Because of radiation from electrons, the process observation is not as accessible as other AM technologies, only through a leaded-glass viewport. Therefore, what exactly happens inside the build chamfer is not as well perceived as other AM processes. Recently, Oak Ridge National Laboratory published a video animation of the EBAM process [4] that offers good illustrations of the process details, especially to those without access to an EBAM machine.

\section{Applications and challenges}

Due to EBAM's unique capability, it is especially beneficial to such industries as the aerospace sector, creating new opportunities for both prototyping and low volume productions. The time, cost, and challenges of machining or other processes are eliminated, which makes the components readily available for functional testing or installation on a system, e.g., aircraft [5]. Additionally, the additive process opens a door to new design configurations (e.g., cellular structures) and weight-reduction alternatives.

The energy density of the electron beam is high enough to melt a wide variety of metals and alloys. EBAM processes have the potential to work with many material classes, for example, aluminum alloys [6], stool steel (H13) [7], and cobalt-based superalloys [8], etc. However, Ti alloys, in particular, Ti-6Al-4V, were the first material extensively researched, also widely used in EBAM technologies. Ti alloys have numerous potential applications as a consequence of their superior properties: low density, high mechanical strengths, corrosion resistance, human allergic response, and good biocompatibility [9-11]. The industrial processing routes for titanium alloys include ingot casting, powder processing, ingot forging, and sheet production by hot-rolling. Using traditional processes makes it difficult to manufacture highly complex and functional Ti-alloy parts, such as artificial knee joints, hip joints, and bone plates, etc. EBAM has been used for fabrications of specific netshaped parts for use within both aerospace and medical implant industries. The fabrication of implants from patient specific data with adaptation to the region of implantation is made possible with EBAM (e.g., temporomandibular joint prosthesis in Figure 2a), eliminating expensive secondary processing such as machining or forming and related lead times. Moreover, with geometric freedom, EBAM has enabled one step fabrications of intricate architecture (meshed, porous, cellular), e.g., porous custom implants with controlled porosity to meet the requirements of the anatomy and functions at the region of implantation. In addition, EBAM has been used to assist the Environmental Control and Life Support System (ECLSS) group of NASA for a new design of hardware, Figure $2 b$, to pack zeolite materials for improving $\mathrm{CO}_{2}$ removal from the International Space Station environment [12]. Using EBAM, the total production time is 1 week including machining the matted surfaces in contrast to 13 weeks when using traditional processes. In addition, the ability to produce a negative Poisson's ratio structure, the so-called "auxetic behavior" is another unique capability of EBAM. A negative Poisson' ratio leads to higher impact and shear resistances, and fracture toughness. Schwerdtfeger et al. [13] found negative Poisson's ratios in the range of -0.2 to -0.4 depending on the orientation.

Since Ti-6Al-4V is the most widely used material in EBAM, the major effort of this review is focused on this group 

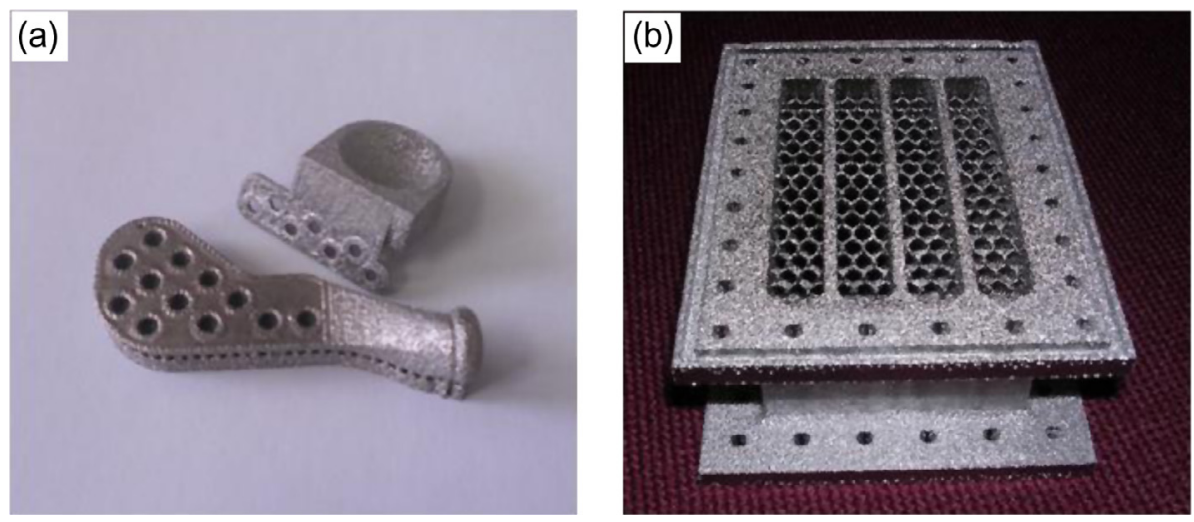

Figure 2. (a) Prototype of temporomandibular joint prosthesis, and (b) ECLSS test chamber [12], both produced by EBAM.

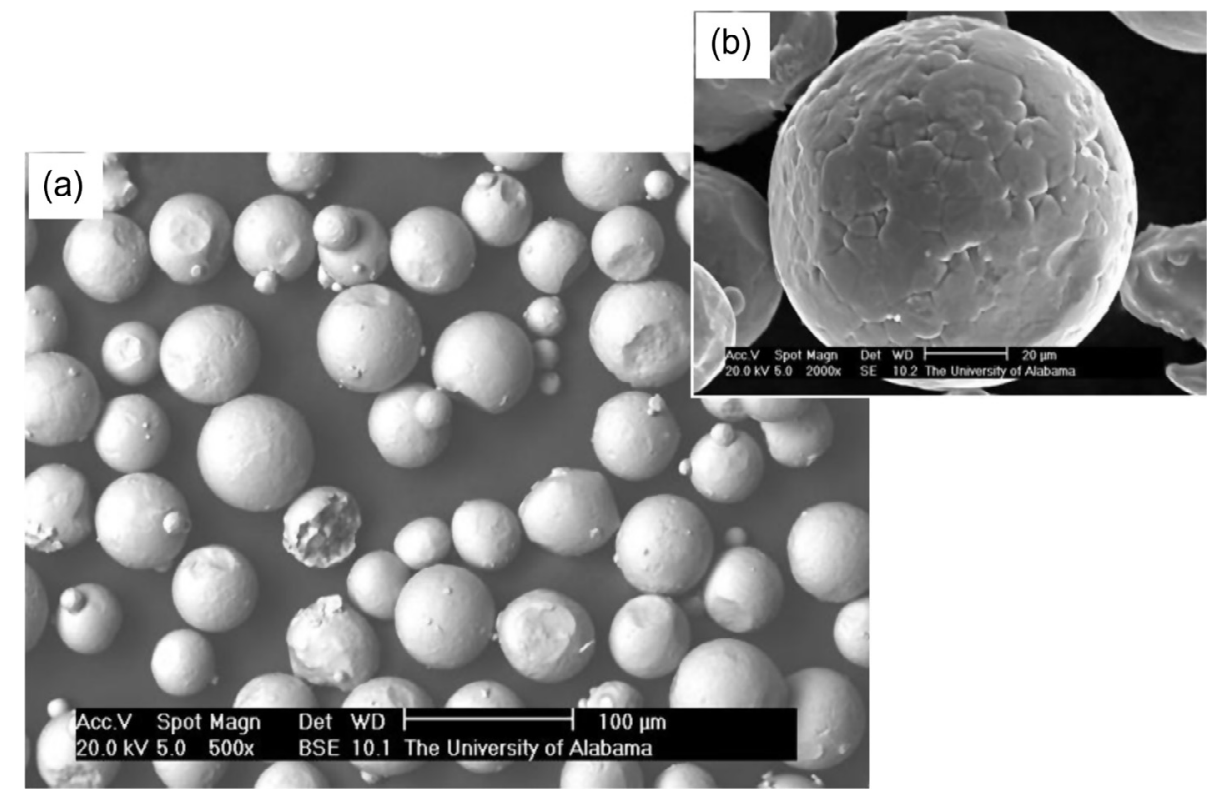

Figure 3. SEM images of Ti-6Al-4V powder: (a) particles with different sizes and (b) an individual particle.

of materials, its usages, applications and EBAM part characteristics.

\section{Powder characteristics}

\section{Raw powder}

Raw materials used in EBAM are metallic particles from powder metallurgy, and the characteristics and quality of powder strongly affect the process performance. The powder morphology is one important factor in EBAM affecting processing conditions such as flowability, powder packing, and ultimately, heat transfer process phenomena [14]. NeiraArce observed that the powder used in EBAM is spherical in shape. The spherical shape may contribute to improved flowability, and thus, may ensure high build rates and part accuracy [14].
In general, fine powder is used in EBAM. Figure 3 shows scanning electron microscopic (SEM) images of Ti-6Al-4V powder: (a) low magnification showing a population of particle sizes and (b) high magnification of an individual powder. The powder size distribution also has a significant effect on the build part density, surface finish and mechanical properties [14]. Syam et al. [15] studied the size distribution of Ti-6Al-4V powder in EBAM and reported the size range as from 45 to $100 \mu \mathrm{m}$. Murr et al. [9] also investigated the distribution of Ti-6Al-4V powder diameters. The spherical powder diameters were measured and plotted in a histogram, shown in Figure 4. It is noted that the powder size distribution is bimodal. The average overall powder diameter in Figure 4 is $30 \mu \mathrm{m}$. The average sizes of large particles and small attached particles are around $60 \mu \mathrm{m}$ and $10 \mu \mathrm{m}$, respectively. For the chemical composition, according to a study by Murr et al. [9], Ti-6Al$4 \mathrm{~V}$ powder used in EBAM has a nominal composition of $6.04 \% \mathrm{Al}, \quad 4.05 \% \mathrm{~V}, 0.013 \% \mathrm{C}, 0.07 \% \mathrm{Fe}, 0.13 \% \mathrm{O}$, 


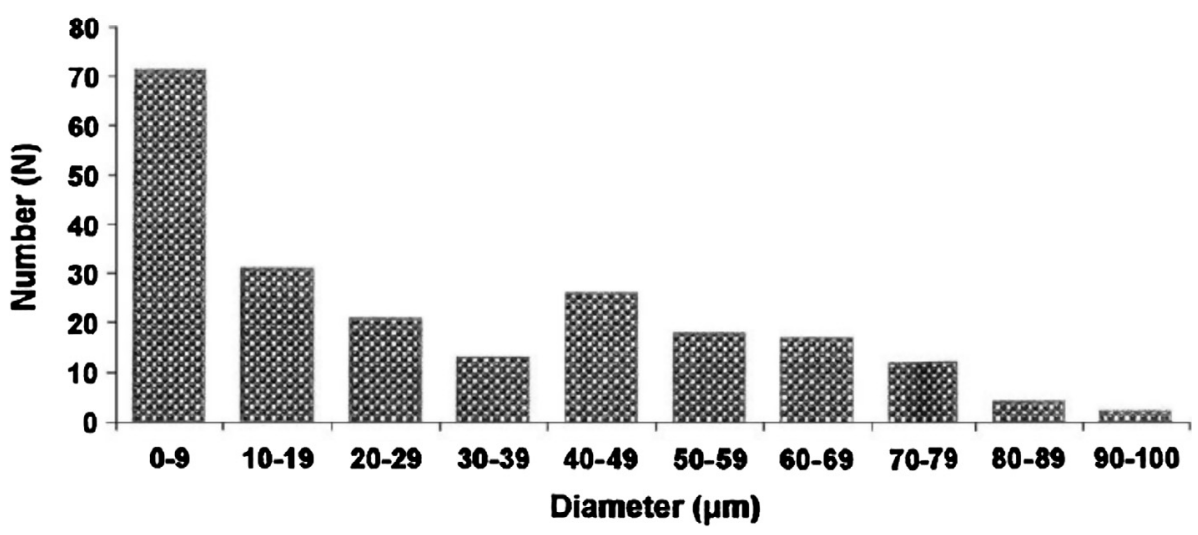

Figure 4. Histogram of raw Ti-6Al-4V particle size distribution [9].
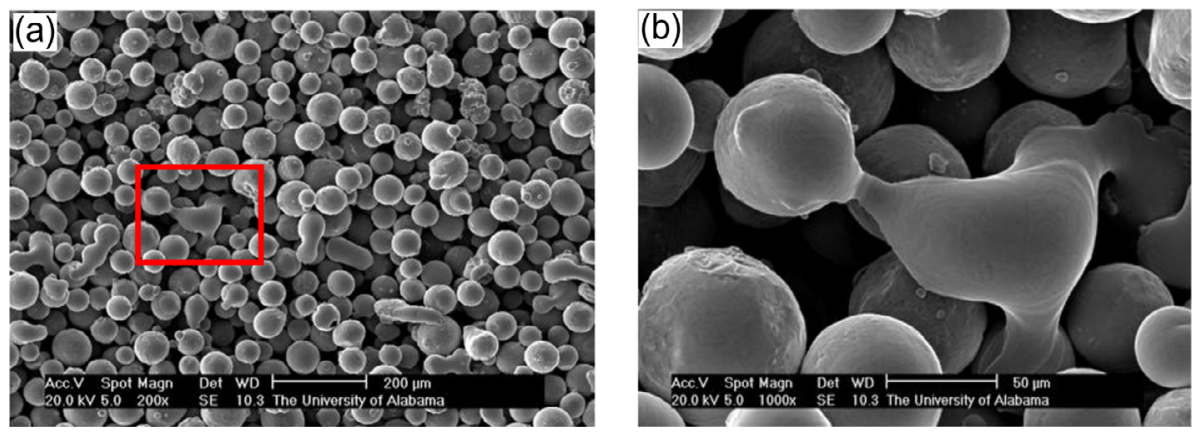

Figure 5. SEM images of sintered Ti-6Al-4V particles from preheating.

$<0.005 \% \mathrm{~N}$ and $\mathrm{H}$; the balance is $\mathrm{Ti}$ (in weight percent), comparable to the common Ti-6Al-4V specification.

\section{Sintered powder}

The thermal cycle in EBAM, which includes the preheating, subsequent melting and solidification, is critical to determine the microstructure and mechanical properties of the EBAM parts. Different from the laser additive manufacturing process, the EBAM process applies the preheating to lightly sinter the precursor powder layer by using electron beam at a low power and a high scanning speed. According to the study by Cormier et al. [7] and Rodriguez et al. [16], the preheating process serves two purposes: holding the metal powder in place during the subsequent melting scan and reducing the thermal gradient in the build part.

$\mathrm{He}$ et al. [17] studied preheating of Ti-6Al-4V powder in EBAM. According to the authors, the sintering mechanism is that small particles partially or completely melt and they play an important role as a binder to bond the majority of large particles together, which will not only hold the particles and withstanding the impact from electrons, but also prevent the spheroidization effect in the part surface. Gong and Chou [18] also investigated the morphology of the sintered powder in EBAM. The phenomenon of necking could be noted on both the build and side surfaces. Figure 5 illustrates the SEM images of the aggregated powder on the scanning surface. The diameter of the necks is on the order of $1-10 \mu \mathrm{m}$.
The preheating process contributes to the metallurgical bonds or even partial melting of the powder.

\section{Microstructures}

Typically, Ti-6Al-4V samples from EBAM show an ordered lamellar microstructure, consisting of extremely fine grains, as can be expected by the thermal characteristics of the EBAM process: small melt pool and rapid cooling. EBAM components possess a columnar shaped morphology of the prior $\beta$ phase with a growing direction parallel to the build direction [19], which is a consequence of primary thermal gradients that exist in the build direction. Antonysamy et al. [20] studied the prior $\beta$-grain texture of EBAM components. It is shown that the columnar structure shows strong fiber texture of $<001>\beta$, which is normal to the deposited powder layers. The favored texture could be attributed to the highly elongated shape of the moving melt pool and the raster pattern used in the EBAM process. The phases of EBAM Ti-6Al-4V samples include some $\alpha$ phase at the $\beta$ grain boundaries, which is finer than that obtained by metal casting [21]. Facchini et al. [22] investigated microstructures by X-ray diffratometry (XRD) and reported that the main constituent is $\alpha$ HCP phase with only a small contribution of $\beta$ phase in EBAM Ti-6Al-4V. The HCP pattern can be attributed to both $\alpha$ phase and the $\alpha^{\prime}$-martensite, which is spatially smaller than the $\alpha$-phase platelets. Safdar et al. [19] also reported that a typical $(\alpha+\beta)$ structure, namely Widmanstätten $\alpha$ platelets with rod-like $\beta$ phase, formed 

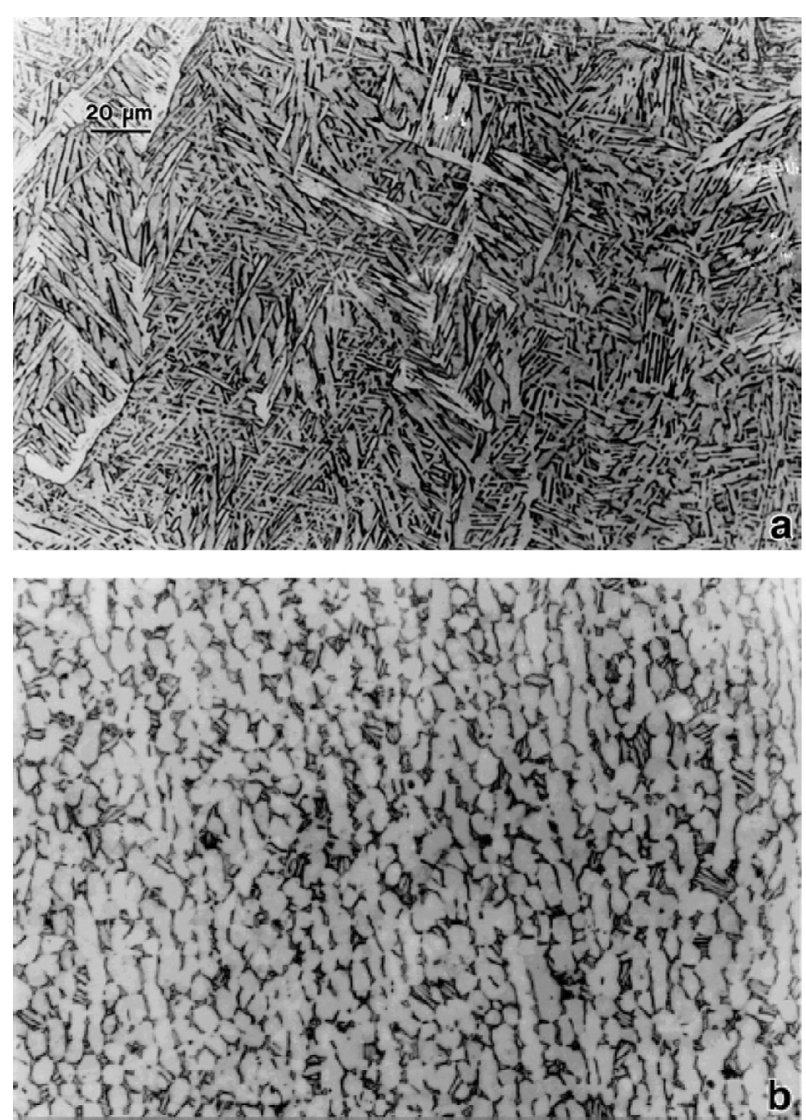

Figure 6. Microstructures of Ti-6Al-4V specimens made by (a) EBAM vs. (b) casting [9].

at the interfaces of the fine $\alpha$ grains, have been observed in the columnar prior $\beta$ grains. Grain boundary $\alpha$ phase was found to be formed around the boundaries of the columnar prior $\beta$ grains. Koike et al. [23] compared the EBAM microstructures to counterparts from cast and wrought Ti specimens. For the cast specimen, a typical $\alpha$-case microstructure consisting of columnar $\alpha$-crystals can be clearly observed. The microstructure of the wrought Ti-6Al-4V specimen consisted of slightly elongated $\alpha$ grains and intergranular $\beta$ grains which is a typical microstructure from heat treatment conditions. On the other hand, no $\alpha$-case was observed near the surface of the EBAM specimens. However, Murr et al. [9] observed that the EBAM Ti-6Al-4V prototypes exhibit the $\alpha$-phase, acicular platelet microstructures similar to commercial wrought products, while the mesh and foam prototypes exhibit mainly $\alpha^{\prime}$-martensitic platelets or mixtures of $\alpha$ and $\alpha^{\prime}$ platelets, giving rise to harder structures and consequently greater strengths. Figure $6 \mathrm{com}-$ pares the microstructures of Ti-6Al-4V specimens from (a) EBAM and (b) casting [9]. The authors of this paper have attempted to study the microstructure of Ti-6Al-4V parts processed by EBAM. The microstructure of Ti-6Al-4V consists of columnar grains of prior $\beta$ growing along the build direction, as can be seen from Figure 7a. The width of the columnar structure is about $25-30 \mu \mathrm{m}$. After the solid phase transformation in EBAM, the prior $\beta$ grain structure transforms to a bulk microstructure of fine Widmanstätten $(\alpha+\beta)$ structure and martensite $\alpha^{\prime}$ owing to the rapid cooling process. Figure $7 \mathrm{~b}$ illustrates the microstructure of the scanning surface of an EBAM Ti-6Al-4V sample, with "equiaxed" grains shown. It demonstrates that the prior columnar structure is generally rod-shaped. There are also studies reporting different microstructures (grain size and morphology) obtained from the EBAM, attributed to noticeably different cooling rates [24, 25] and re-melting [26]. As to the chemistry specification, Heinl et al. [27] tested the element composition of the EBAM parts. The authors claimed that the composition of the EBAM parts conforms to the standard specifications for Ti-6Al-4V alloy castings for surgical implants. However, Gayten et al. reported that the chemistry of EBAM made Ti-6Al-4V parts may have 10 to $15 \%$ reduction in $\mathrm{Al}$ content [28] possibly due to a higher vapor pressure of Al.

The gas voids or porosities are a typical defect in EBAM parts, which is exemplified in Figure 8 below. Gaytan et al. [28] investigated porosity defects and control during EBAM and attempted using hot-isostatic-pressing (HIP) to eliminate gas voids in built samples. The result showed that while the voids can be largely eliminated by a single standard HIP cycle, remnants sometimes persist. In addition, some gas bubbles actually came from recycled powder and stay in EBAM-built parts. Because of the melt and liquid phase surface tension as well as the low gas pressure, it is essentially impossible to eliminate the intrinsic gas bubbles in EBAM parts. Reported by Gaytan et al., however, because of the small void size (order of $10 \mu \mathrm{m}$ ), they may not impact the mechanical properties of EBAM-built parts.

In addition, electron beam-material interactions reduce the EBAM process stability. The melt pool instability is affected possibly by an inadequate energy density transmitted from the electron beam into the powder, and it may result in the balling effect, when the surface tension of molten liquid exceeds the wetting ability of the previously solidified layer [29]. The melt balls further prevent the process from continuation due to rough textures of the top layer. Moreover, as EBAM relies on selective solidification of the top powder layer, energy is inserted into the material in a non-uniform way. Large temperature gradients may emerge due to selective heating of powder areas and thus, residual stresses may be induced. If the residual stresses exceed the bonding abilities between layers, it results in delamination, which depends on the scanning strategy [30]. Specifically, the orientation of the scan vectors has a considerable influence to delamination [3].

It has been reported that operating parameters have significant effects on the part characteristics [24, 25], quality consistency and process performance. Murr et al. reported that variations in melt scan, beam current, and scan speed affect the EBAM built defects such as porosity [24], and may cause significant property-performance variations [31]. In general, the beam power, diameter, and speed, as well as the pre-heat temperature are four major process parameters; the first three are tied to the thermal cycle variables, temperatures and cooling rates, and the pre-heat temperature governs the sintering state of powder prior to the melting scans. Puebla et al. [32] studied the effect of the scan speed on microstructure and macrostructure of EBAM Ti-6Al-4V. When the scan speed is increased from 100 to $1000 \mathrm{~mm} \cdot \mathrm{s}^{-1}$, the cooling rate and solidification speed both increase, which results in a decreasing $\alpha$-phase acicular grain width as well as an increasing proportion of martensite plate production. Correspondingly, increasing the scan speed 

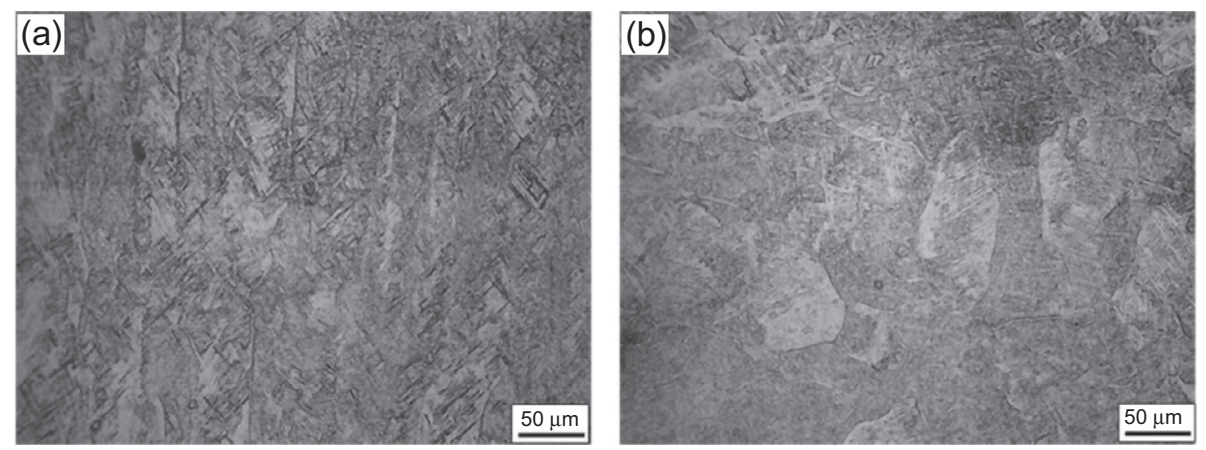

Figure 7. Optical metallograph of EBAM Ti-6Al-4V: (a) side surface and (b) scanning surface.

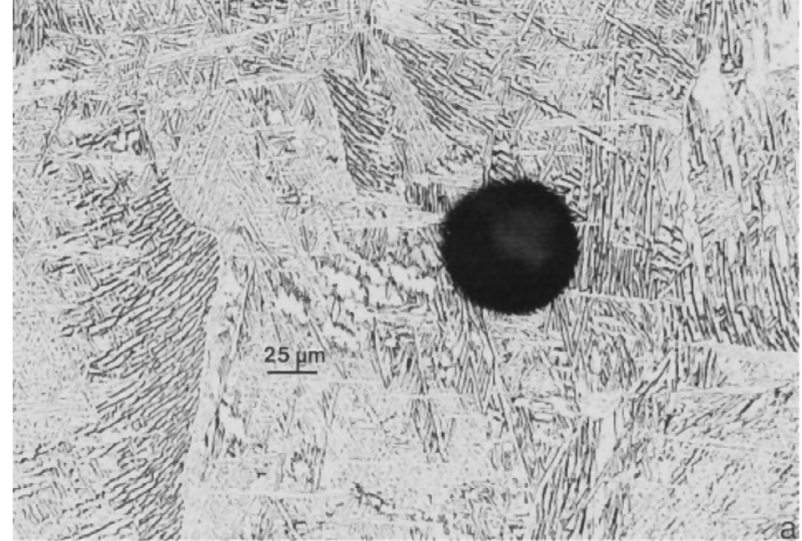

Figure 8. An example of gas void: optical metallograph of a polished and etched section [28].

increases the porosity by creating unsintered powder volumes within the layers. In addition, Hrabe and Quinn [33] investigated the effect of energy input on the microstructure of the built parts. It was found that the melt pool size, $\alpha$ lath thickness and prior- $\beta$ grain size increased with the increase of energy input.

Rapid self-cooling, which results in the EBAM layer building/bonding mechanism, has been noted to be different upon comparing different melt-scan parameters. Gaytan et al. reported that in Ti-6Al-4V, the differences in melt-scan parameters create microstructural variations characterized by sizes or dimensions as well as phase differences and dislocation density variations [28]. Bontha et al. [25] investigated the effects of process parameters on solidification microstructures in beam-based fabrications. It shows that variations in the beam power and speed can alter both solidification cooling rates and thermal gradients by several orders of magnitude, which have a significant effect on resulting microstructures. Results specifically for Ti-6Al-4V suggest that process size-scale can have a significant effect on microstructures, including a transition from columnar to equiaxed microstructure at higher powers.

\section{Mechanical properties}

EBAM part properties have been frequently investigated. Some studies indicated that properties of EBAM parts are comparable to those from conventional processes (wrought) [9, 34].
However, other research indicated improved hardness of EBAM parts [35]. Changes in local chemistry and different microstructures have been suggested as possible causes.

\section{Tensile testing}

Tensile testing has been widely used to characterize the mechanical properties of EBAM parts. Some researchers [22] found that the ultimate tensile strength (UTS) of EBAM built specimens is higher than the wrought or annealed ones, with a lower ductility. However, others [23] presented that the UTS and ductility of the cast and wrought Ti-6Al-4V specimens were higher than those of EBAM counterparts. The reason for the difference could be attributed to the variation in the built parameters, which result in different structures such as composition, structures, pore size, and porosity distribution, etc. Hrabe and Quinn [33] also studied the effect of energy input on the mechanical properties of the EBAM built parts. The results show that UTS, yield strength (YS) decreased with the increase of energy input. However, the change in UTS (2\% change) and YS (3\% change) was small. Ladani and Roy [36] investigated the anisotropic effect on the mechanical behavior of Ti-6Al-4V manufactured by EBAM. Tensile testing indicated that YS and UTS for flat-build samples have distinguishably higher values than those of the side-build and top-build samples.

Koike et al. [23] investigated and reported that the YS and UTS of the EBAM specimens were 735 and $775 \mathrm{MPa}$, respectively. The ductility was $2.3 \%$ elongation. These values were comparable to those of cast specimens, which exhibited slightly higher UTS and ductility. These differences were considered to be due to rippled, rough specimen surfaces and possibly higher oxygen content in the EBAM specimens ( 0.34 vs. $0.22 \%$ ), originated from the alloy powder. Other researchers showed better ductility (elongation) in EBAM parts. Murr et al. [9] studied that the elongation of the EBAM samples shown is about $16-25 \%$ compared to the elongation of $12-14 \%$ for wrought alloys. Table 1 below summarizes the mechanical properties of EBAM vs. wrought Ti-6Al-4V specimens.

\section{Compressive strength}

Compressive testing has also been used to evaluate EBAM parts, mainly for meshed, porous, or cellular structures 
Table 1. Comparisons between EBAM and wrought Ti-6Al-4V.

\begin{tabular}{|c|c|c|c|c|c|}
\hline & YS (GPa) & UTS (GPa) & Ductility (\%) & $H(\mathrm{GPa})$ & Ref. \\
\hline \multirow[t]{3}{*}{ EBAM } & $1.10-1.15$ & $1.15-1.20$ & $16-25$ & $3.8-4.1$ & [9] \\
\hline & 0.83 & 0.915 & - & 3.2 & [22] \\
\hline & 0.735 & 0.775 & 2.3 & 3.619 & [23] \\
\hline \multirow[t]{3}{*}{ Wrought } & $1.17-1.22$ & $1.23-1.29$ & $12-14$ & $3.8-4.3$ & [9] \\
\hline & 0.79 & 0.87 & - & - & [22] \\
\hline & 0.860 & 0.931 & 14 & 3.207 & [23] \\
\hline
\end{tabular}

in biomedical applications. Li et al. [37] utilized EBAM to fabricate porous Ti-6Al-4V parts with fully interconnected, controlled internal pore architecture. The compressive test showed that a linear elastic deformation stage, followed by a long plateau stage with a nearly constant flow stress to large strains, in which cells collapse due to buckling and plasticyielding, and the final stage with the stress reaching the maximum value. The authors reported that $66 \%$ porosity Ti-6Al-4V parts has a compressive strength approximately $116 \mathrm{MPa}$ and the Young's modulus of $2.5 \mathrm{GPa}$, close to the human cancellous bone.

Parthasarathy et al. [11] reported the stiffness and elastic modulus for the open cellular Ti-6Al-4V foams varied with density consistent with the Gibson-Ashby foam model [38]. Moreover, the stiffness varies inversely with porosity or pore density consistent with literature values for a number of metal and alloy systems, especially aluminum. The authors also reported that both compressive stiffness and strength decrease with an increase in the porosity. Heinl et al. [39] investigated cellular Ti-6Al-4V structures with a controllable interconnected porosity by EBAM. The mechanical properties of the structures were examined under compression load and compared with the properties of human bone. It is found that cellular solids have an important influence to their stiffness and strength.

\section{Other testing}

Other types of mechanical testing such as hardness tests and flexural tests have also been used in studying mechanical properties of Ti alloys processed by EBAM. Koike et al. [23] investigated EBAM Ti-6Al-4V specimens by Vickers microhardness testing. The hardness of EBAM specimens were higher than that of the cast or wrought specimens, which is probably attributed to finer $\alpha / \beta$ lamellar microstructures according to Hall-Petch relation [40, 41]. Karlsson et al. [42] conducted the nanoindentation test of EBAM components with two different Ti-6Al-4V powder sizes (diameters of 45-100 $\mu \mathrm{m}$ and $25-45 \mu \mathrm{m})$. The results show that the Young's modules and hardness were not significantly affected by the powder size or the layer thickness within the range of studied process parameters. However, the part surface appearance was noted to be different with the different powder sizes. Additionally, Cansizoglu et al. [29] investigated EBAM Ti-6Al-4V bars using a three-point bending tester. The results of the flexure tests showed that the elastic properties of the structures are relatively consistent between builds.

\section{Geometric attributes}

Even with impressive advantages over conventional manufacturing technologies, EBAM still exhibits several process challenges, such as dimensional accuracy and surface finish. Despite an intense interest in attainable accuracy and strengths by EBAM [43], few studies have emphasized the geometric aspects in EBAM. Cooke and Soons [44] studied the geometric accuracy of metallic test part manufactured by EBAM and other powder-based processes. The model was a circle-diamondsquare test part with an inverted cone that is used to evaluate the performance of five-axis milling machines. The authors reported that overall, the observed errors of EBAM parts are significantly larger than those of typical machined parts by at least an order of magnitude. The errors seem to be repeatable, providing opportunities for compensation strategies. In addition, errors of parts may be due to the process; cyclic thermal effects, including deformations due to residual stresses, are most likely the cause.

In research conducted by Koike et al. [23], an enlarged view of the gauge section of the EBAMTi-6Al-4V specimen shows a rough exterior appearance compared to as-cast counterparts. The surface of the EBAM specimens are covered by rippled layers. On the other hand, the exterior surfaces of cast specimens are much smoother. Figure 9 below shows the surfaces of EBAM Ti-6Al-4V parts (tensile specimens), exhibiting the scanned pattern (Figure 9b) and surface morphology from a white-light interferometer (Figure 9c). The surface has a roughness about $20 \mu \mathrm{m}$ of $R_{\mathrm{a}}$. On the other hand, it has also been suggested that as-fabricated rippled surfaces of EBAM processed alloys may be beneficial in some biomedical applications where an irregular surface is desired.

\section{Other materials used in EBAM}

In addition to widely used Ti alloys, EBAM has also been used with other metal-based materials including intermetallics, tool steels, superalloys and copper, etc.

Titanium aluminide, a TiAl-based intermetallic, has been used for propulsion exhaust system components and other aerospace applications. Murr et al. [45] characterized the microstructures of TiAl powder and solid TiAl components fabricated by EBAM. The EBAM process results in a phase transformation: the powder was $\alpha_{2}$-phase-rich (HCP), while the EBAM components were largely $\gamma$-TiAl (FCC). The EBAM specimens exhibited an equiaxed $\gamma$-TiAl grain structure with a 


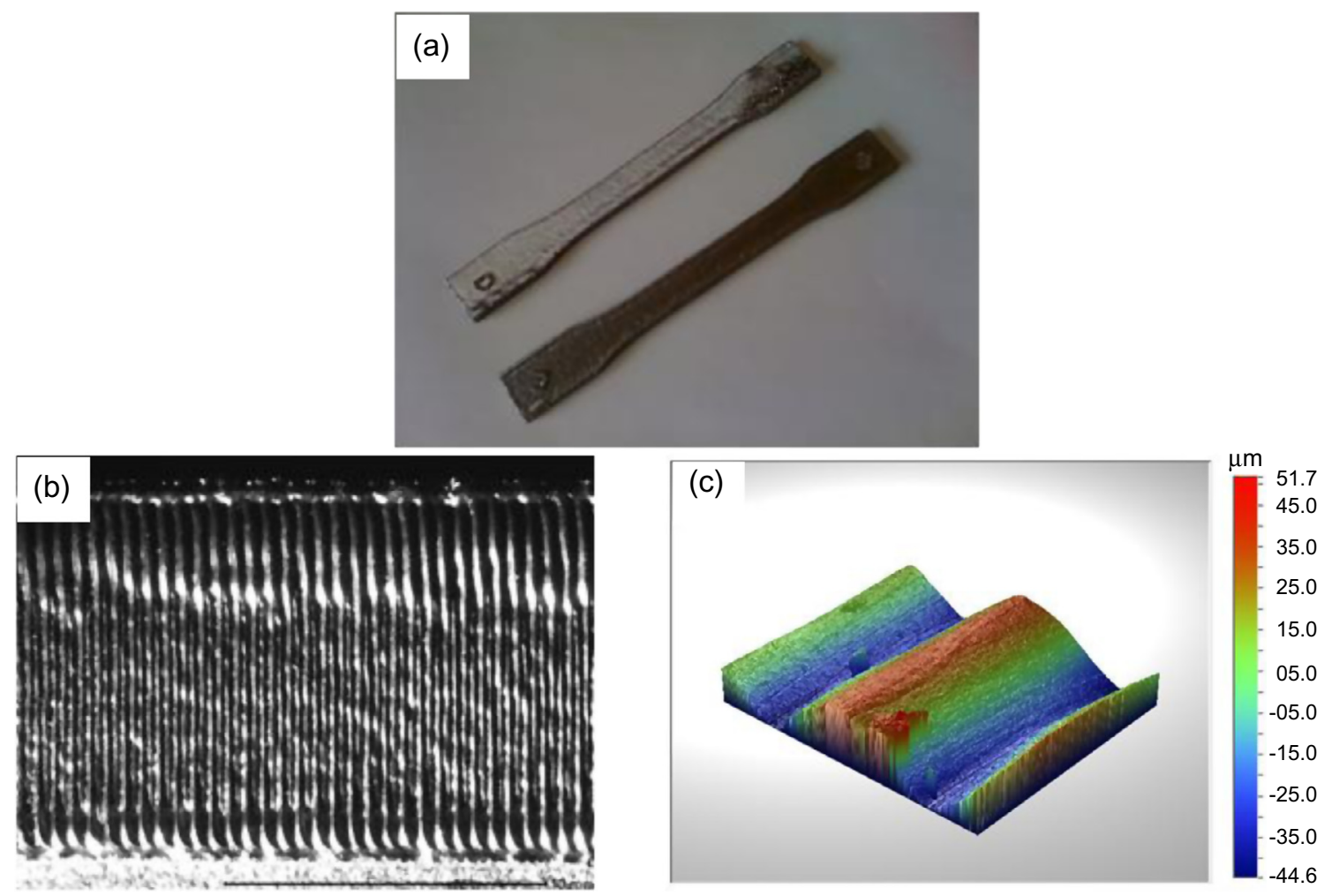

Figure 9. Exterior surfaces of (a) EBAM Ti-6Al-4V samples showing: (b) the scan path and (c) surface morphology.

lamellar $\gamma / \alpha_{2}$ colony structure within the $\gamma$-grains. A relatively high dislocation density contributed to residual hardness, due in part to rapid cooling, associated with EBAM process. Heat treatment is generally required to adjust the microstructure and increase mechanical properties of EBAM TiAl parts. Sabbadini et al. [46] studied the effects of HIP treatments. It was shown that HIP produces a tempered microstructure, with near $\gamma$ equiaxed morphology, resulted from an almost full recrystallization and little grain growth. Biamino et al. [2] also investigated the mechanical properties of both as-fabricated EBAM TiAl specimens and after HIP. After HIP, YS appears to be fairly temperature independent up to $815^{\circ} \mathrm{C}$.

H13 steel is a popular and versatile, hot-work steel, providing good balance of toughness, thermal crack resistance, and high temperature strength needed for forming tooling. Cormier et al. [7] studied the microstructure and properties of $\mathrm{H} 13$ steel produced by EBAM. The authors reported that EBAM H13 parts exhibit full interlayer bonding with virtually no porosity. The as-fabricated material was martensite having a hardness of 48-50 HRC. After annealing, HRC value was under 20. A small number of isolated shrinkage cracks confined within specific layers could be observed.

Co-based alloys are a group of bone implant materials. Murr et al. [47] investigated the microstructure and mechanical properties of EBAM processed Co-29Cr-6Mo alloy. The EBAM fabricated solid, mesh, and foam Co alloy prototypes all exhibited a directional, columnar $\mathrm{Cr}_{23} \mathrm{C}_{6}$ precipitate architecture parallel to the EBAM build direction intermixed with some stacking faults in the FCC matrix. The columnar precipitates were spaced within textured, directional grains. Following
HIP-annealing, the columnar precipitates dissolved and were replaced by a higher density of intrinsic stacking faults, resulting in hardness essentially constant, while there was a slight drop in YS, but UTS increased by $20 \%$. Gaytan et al. [48] also investigated the EBAM process on Co-Cr-Mo alloys. The tensile testing of specimens fabricated by EBAM produced average UTS of $1.45 \mathrm{GPa}$, YS of $0.51 \mathrm{GPa}$, and an elongation of $3.6 \%$, which are better than wrought or cast Co-Cr-Mo alloys. Sun et al. [49] studied microstructure and high temperature tensile properties of the Co-28Cr-6Mo- $0.23 \mathrm{C}-0.17 \mathrm{~N}$ alloy fabricated by EBAM. The authors found that the preferential crystal orientations of the $\gamma$ phase in the as-EBAM-built $0^{\circ}$-, $45^{\circ}$-, $55^{\circ}$ - and $90^{\circ}$-samples along the cylindrical axial directions

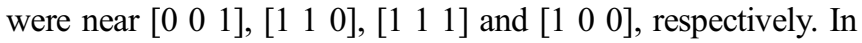
addition, $\mathrm{M}_{23} \mathrm{C}_{6}$ precipitates were observed to align along the build direction with intervals of around $3 \mu \mathrm{m}$ in all of the samples. The sample built with $55^{\circ}$ deviation from the $Z$ axis had the highest UTS of $806 \mathrm{MPa}$ at $700{ }^{\circ} \mathrm{C}$.

Ramirez et al. [50] investigated the effects of precipitate $\left(\mathrm{Cu}_{2} \mathrm{O}\right)$ on the microstructure and mechanical properties of EBAM Cu parts. These precipitate-dislocation architectures create increased hardness, ranging from a base-plate hardness of HV 57 to an EBAM part hardness of HV 88, referenced to the precursor powder containing $\mathrm{Cu}_{2} \mathrm{O}$ precipitates that has a hardness of HV 72.

Nickel-based superalloys present prominent high-temperature, corrosion and oxidation resistance applications including jet engine components. Murr et al. [51] investigated Ni-based superalloys regarding to the effects of heat treatment on the mechanical properties of EBAM built parts. Tensile properties 
Table 2. Property comparisons between EBAM and wrought Ti-6Al-4V.

\begin{tabular}{llll}
\hline Material & \multicolumn{1}{c}{ Application } & \multicolumn{1}{c}{ Mechanical properties } \\
\hline TiAl & High temperature, propulsion exhaust system & YS/UTS $\left(700{ }^{\circ} \mathrm{C}\right): \sim 300 \mathrm{MPa}, 360 \mathrm{MPa}$ & {$[2,45,46]$} \\
$\mathrm{H} 13$ & Tool, die/mold & As-processed hardness of 48-50 HRC & Micro-hardness: 4.4 to 5.9 GPa \\
$\mathrm{Co}-\mathrm{Cr}$ based alloys & High temperature bearings, biomedical implants & Micro-hardness: 88 HV & [47, 48] \\
$\mathrm{Cu}$ & Electrical & YS/UTS (538 $\left.{ }^{\circ} \mathrm{C}\right): 300 \mathrm{MPa}, 610 \mathrm{MPa}$ & [50] \\
$\mathrm{Ni}$ based alloys & Jet engine parts & {$[51]$} \\
\hline
\end{tabular}

of EBAM cylinders at $538{ }^{\circ} \mathrm{C}$ didn't significantly alter microhardness from as-fabricated cylinders tested at room temperature, but YS dropped from 0.33 to $0.30 \mathrm{GPa}$, and UTS decreased by $23 \%$. The corresponding elongation increased from 44 to $53 \%$. Similarly, the fabricated and HIP-ed cylinders tested at $538{ }^{\circ} \mathrm{C}$ also illustrated no significant change in microhardness, but both YS and UTS decreased marginally with little increase in ductility comparing to tests at room temperature. By comparison, wrought $\mathrm{Ni}$ superalloy tested at $538{ }^{\circ} \mathrm{C}$ exhibited a YS of $280 \mathrm{MPa}$ and a UTS of $830 \mathrm{MPa}$.

Table 2 below briefly summarizes different materials that have been tested in EBAM, their corresponding applications and properties.

\section{Process simulations}

Despite the potential benefits of EBAM technologies and increasing studies/reports of this process, mostly applications, case studies, microstructures/properties, there has been little literature in process modeling/simulations of EBAM. EBAM is a rather complicated process and fundamental understanding of process physics is a key to improve the process performance and part quality consistency. Due to temperature dependent material properties and a moving heat source, an analytical solution of the thermal process model is considerably demanding. Zäh and Lutzman developed a simplified heat transfer model of EBAM to study the scan speed and beam power effects on the weld-pool geometry [3]. Therefore, the mathematical-physical model is being transferred into a simulation software based on the finite-element (FE) method and thus, melt pool instabilities as a function of various input parameters can be predicted. Three different melt pool conditions are compared with each other. The melt pool shapes at the beam power (PB) of $150 \mathrm{~W}$ vary significantly with the applied scanning speed, $V_{\mathrm{S}}$. Within the compared results, the parameter combination $V_{\mathrm{S}}=50 \mathrm{~mm} / \mathrm{s}$ and $\mathrm{PB}=150 \mathrm{~W}$ yields the minimum lengthto-width ratio of approximately 1.3 . The authors were able to define a suitable process window, however, acknowledged a more comprehensive model is needed if new materials are to be utilized.

Shen and Chou recently initiated a study to investigate the thermal phenomenon of the EBAM process. A finite element (FE) model incorporating Gaussian heat flux distribution, fusion latent heat, temperature-dependent thermal properties was developed to study the thermal response when subject to a moving source of heat of high intensity [52]. Figure 10 below shows an example of temperature contours in the part during the process. The results are temperature contours of a half part modeled (because of symmetry) around the beam center at the

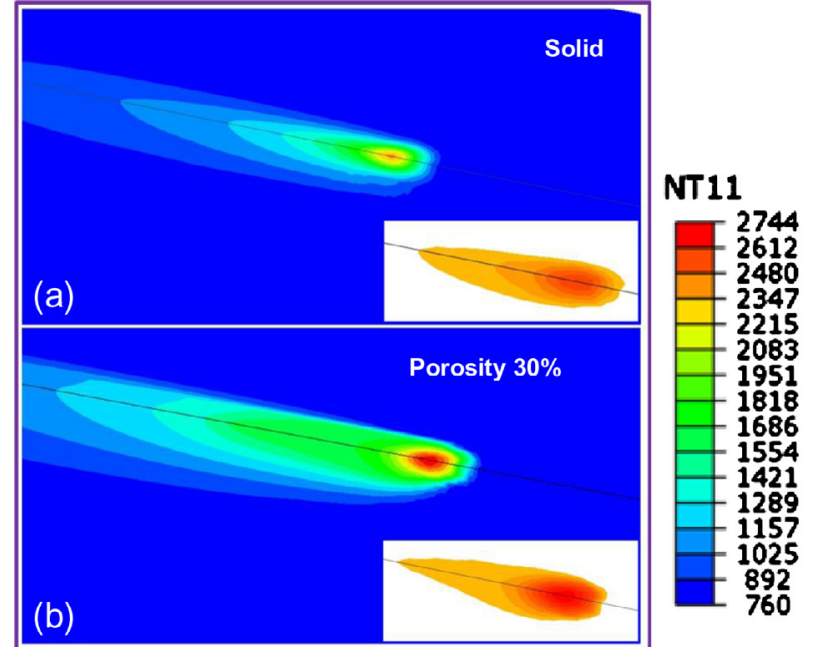

Figure 10. Temperature fields and melt pool geometries of (a) solid vs. (b) powder top layer [52].

quasi-steady state. High temperatures with large gradients around the maximum temperature area are noted. It is also noted because the powder porosity strongly affects the thermal conductivity, inclusion of powder as the top layer in the model is required for modeling accuracy. Further, since this is a moving heat source condition, the temperature spatial distributions can be translated to temporal responses to evaluate the corresponding cooling rates. The model, once validated, may be applied to systematically study various issues such as the process parameter effects and the raw material effects.

Jamshidinia et al. [53] applied a coupled computational fluid dynamic (CFD)-FE model to study the heat and thermal stress distribution in EBAM with Ti-6Al-4V powder. According to the numerical results, the negative temperature coefficient of surface tension is responsible for the formation of an outward flow in the molten pool on the top surface during the EBAM. Also, the influence of electron beam scanning speed on the thermal stresses developed in the domain is studied. The heat input and the cooling rate are the dominant factors influencing the level of thermal stresses developed during melting and cooling steps, respectively. The minimum electron beam scanning speed of $100 \mathrm{~mm} / \mathrm{s}$ resulted in the maximum and minimum thermal stresses during melting and cooling steps, respectively.

Körner et al. [54] conducted the mesoscopic simulation of the EBAM process. A 2D lattice Boltzmann model is developed to investigate melting and re-solidification of a randomly packed powder bed under the irradiation of a Gaussian beam during EBAM. Numerical experiments demonstrate that the packing density of the powder bed has the most significant effect on the melt pool characteristics. 

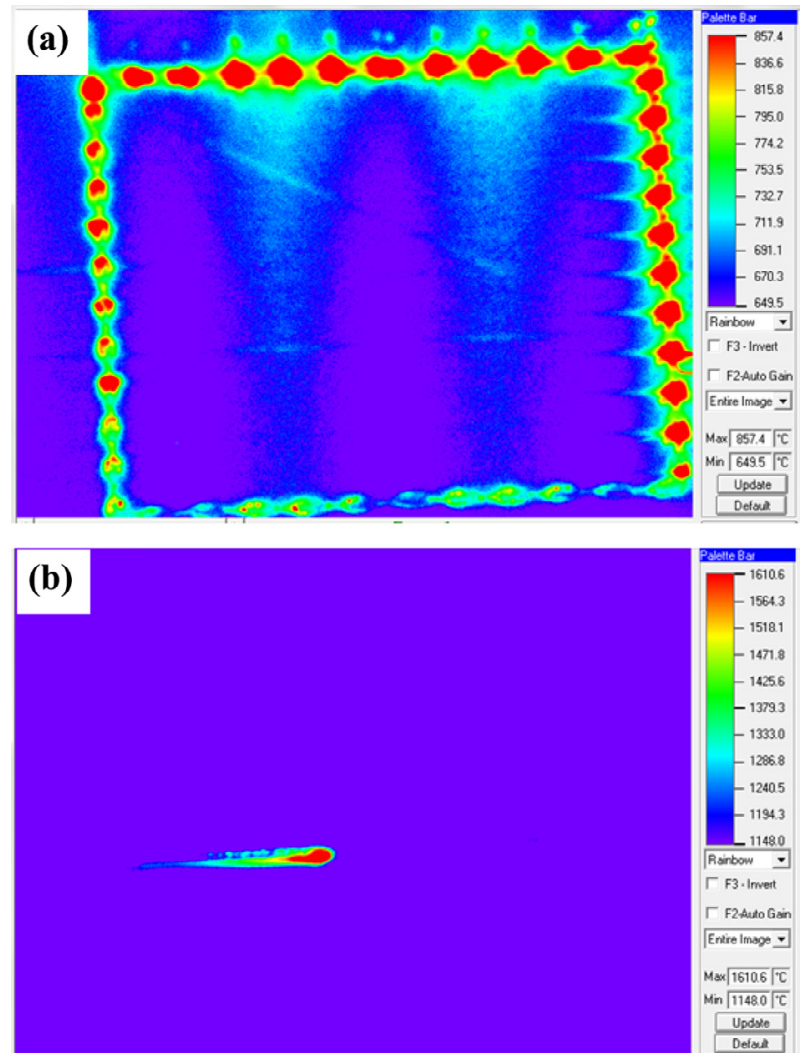

Figure 11. Example of near-infrared thermal images taken during an EBAM building process: (a) during contour melting and (b) during hatch melting.

Moreover, process variable measurements such as temperatures have seldom been reported for EBAM despite the need to validate the simulation model and to monitor the process. Zäh and Lutzman applied thermocouples, attached to the build plate, to evaluate temperature response during EBAM to evaluate the model developed by this research group [3]. However, because of high temperatures and steep gradients, thermocouple techniques are limited in accuracy and resolutions. On the other hand, the authors of this paper have attempted to use a nearinfrared (IR) thermal camera for process temperature measurements in EBAM $[55,56]$. A methodology has also been developed to analyze temperature distributions and history around the melting scan area. A preliminary result is shown in Figure 11 below, displaying examples of thermal images at particular frames collected during the EBAM experiment that built a $25.4 \mathrm{~mm}$ square block. Figure 11a was taken during the contour melting and the square boundary being heated can be observed. Figure 11b was during the hatch melting; at this particular time frame, the electron beam was moving from the left side toward the right. A localized high temperature zone (over $1600{ }^{\circ} \mathrm{C}$ ) with a rapid temperature diminishing tail, similar to, qualitatively, the simulation result (Figure 10) can be noted. In addition, IR-imaging was applied for flaw detection during EBAM by Schwerdtfeger et al. [57]. The method applied demonstrated a good correspondence between the flaws visible in images recorded of an EBAM build using an IR camera and the flaws recorded by traditional metallographic sectioning of the samples after the process was finished.

\section{Conclusions}

EBAM, an enabling technology for design and manufacturing integration, can efficiently assist developments and modifications of products, especially for complex, difficult-tofabricate components. However, the EBAM process physics is complex, and the part characteristics seem to be sensitive to the process parameters, the effects of which may not be well understood. There has been increased literature of EBAM, and this study intends to provide an overview of the EBAM technology, process principles, applications, part microstructures and mechanical properties, and process simulations. The collected and analyzed information from this review can be summarized as below.

1. Though Ti-6Al-4V is the most widely used materials for EBAM, other materials such as intermetallics, tool steels, $\mathrm{Co}-\mathrm{Cr}$ alloys and $\mathrm{Ni}$-based superalloys, and $\mathrm{Cu}$, etc., have been attempted for various applications popularly in the aerospace and biomedical industries, some with unique geometry such as cellular structures.

2. EBAM parts of different raw alloys have been characterized in microstructures and mechanical properties. In general, EBAM parts have very fine microstructures with some porosity, which can be mostly eliminated by HIP. EBAM parts typically have comparable (to wrought counterparts) or superior mechanical properties: high YS and UTS and higher hardness, but a lower ductility.

3. Dimensional errors of EBAM parts are significantly larger than those of typical machined parts by at least an order of magnitude, and yet, surface finish is poorer than cast parts.

4. A thorough literature survey shows limited published studies of EBAM process simulations. To effectively use the EBAM technology, it is necessary to model the process phenomenon and correlate part characteristics with process parameters and variables.

Acknowledgements. The materials presented in this paper are supported by NASA, under Award No. NNX11AM11A.

\section{References}

1. http://www.arcam.com, ArCam AB, accessed in December 2013

2. S. Biamino, A. Penna, U. Ackelid, S. Sabbadini, O. Tassa, P. Fino, M. Pavese, P. Gennaro, C. Badini, Electron beam melting of Ti-48Al-2Cr-2Nb alloy: microstructure and mechanical properties investigation, Intermetallics 19 (2010) 776-781.

3. M.F. Zäh, S. Lutzmann, Modelling and simulation of electron beam melting, Production Engineering 4 (2010) 15-23.

4. http://www.youtube.com/watch?v=BxxIVLnAbLw, Oak Ridge National Laboratory, accessed in December 2013. 
5. J. Hiemenz, Electron beam melting, Advanced Materials \& Processes 165 (2007) 45-46.

6. P. Yu, M. Qian, D. Tomus, C.A. Brice, G.B. Schaffer, B.C. Muddle, Electron beam processing of aluminium alloys, Materials Science Forum 618-619 (2009) 621-626.

7. D. Cormier, O. Harrysson, H. West, Characterization of H13 steel produced via electron beam melting, Rapid Prototyping Journal 10 (2004) 35-40.

8. S.M. Gaytan, L.E. Murr, E. Martinez, J.L. Martinez, B.I. Machado, D.A. Ramirez, F. Medina, S. Collins, R.B. Wicker, Comparison of microstructures and mechanical properties for solid and mesh cobalt-base alloy prototypes fabricated by electron beam melting, Metallurgical and Materials Transactions A 41 (2010) 3216-3227.

9. L.E. Murr, E.V. Esquivel, S.A. Quinones, S.M. Gaytan, M.I. Lopez, E.Y. Martinez, F. Medina, D.H. Hernandez, E. Martinez, J.L. Martinez, S.W. Stafford, D.K. Brown, T. Hoppe, W. Meyers, U. Lindhe, R.B. Wicker, Microstructures and mechanical properties of electron beam-rapid manufactured Ti-6Al-4V biomedical prototypes compared to wrought Ti-6Al-4V, Materials Characterization 60 (2009) 96-105.

10. S.M. Gaytan, L.E. Murr, F. Medina, E. Martinez, L. Martinez, R.B. Wicker, Fabrication and characterization of reticulated, porous mesh arrays and foams for aerospace applications by additive manufacturing using electron beam melting, TMS 2010-139th Annual Meeting and Exhibition-Supplemental Proceeding, Seattle, WA, February 14-18, 2010, pp. 283-290.

11. J. Parthasarathy, B. Starly, S. Raman, A. Christensen, Mechanical evaluation of porous titanium (Ti6Al4V) structures with electron beam melting (EBAM), Journal of the Mechanical Behavior of Biomedical Materials 3 (2010) 249-259.

12. J. Goods, MSFC, private communication, February 2008.

13. J. Schwerdtfeger, P. Heinl, R.F. Singer, C. Körner, Auxetic cellular structures through selective electron-beam melting, Physica Status Solidi B 247 (2010) 269-272.

14. A. Neira-Arce, Thermal modeling and simulation of electron beam melting for rapid prototyping on Ti6A14V alloys, Ph.D. Dissertation, North Carolina State University, Raleigh, NC, 2012.

15. W.P. Syam, A.M. Al-Ahmari, M.A. Mannan, H.A. Al-Shehri, K.A. Al-Wazzan, Metallurgical, accuracy and cost analysis of Ti6A14V dental coping fabricated by electron beam melting process, Proceedings of the 5th International Conference on Advanced Research in Virtual and Rapid Prototyping, Leiria, Portugal, September 28-October 1, 2011, pp. 375-383.

16. E. Rodriguez, F. Medina, D. Espalin, C. Terrazas, D. Muse, C. Henry, E. MacDonald, R.B. Wicker, Integration of a thermal imaging feedback control system in electron beam melting, WM Keck Center for 3D Innovation, University of Texas at El Paso, pp. 945-961.

17. W. He, W. Jia, H. Lin, H. Tang, X. Kang, H. Yu, Research on preheating of titanium alloy powder in electron beam melting Technology, Rare Metal Materials and Engineering 40 (2011) 2072-2075.

18. X. Gong, K. Chou, Characterizations of sintered Ti-6Al-4V powders in electron beam additive manufacturing, Proceedings of the ASME 2013 International Manufacturing Science and Engineering Conference, Madison, WI, June 10-14, 2013, MSEC 2013-1131.

19. A. Safdar, L.Y. Wei, A. Snis, Z. Lai, Evaluation of microstructural development in electron beam melted Ti-6Al-4V, Materials Characterization 65 (2012) 8-15.
20. A.A. Antonysamy, J. Meyer, P.B. Prangnell, Effect of build geometry on the $\beta$-grain structure and texture in additive manufacture of Ti6Al4V by selective electron beam melting, Materials Characterization 84 (2013) 153-168.

21. A. Gulzar, J.I. Akhter, M. Ahmad, G. Ali, M. Mahmood, M. Ajmal, Microstructure evolution during surface alloying of ductile iron and austempered ductile iron by electron beam melting, Applied Surface Science 255 (2009) 8527-8532.

22. L. Facchini, E. Magalini, P. Robotti, A. Molinari, Microstructure and mechanical properties of Ti-6Al-4V produced by electron beam melting of pre-alloyed powders, Rapid Prototyping Journal 15 (2009) 171-178.

23. M. Koike, K. Martinez, L. Guo, G. Chahine, R. Kovacevic, T. Okabe, Evaluation of titanium alloy fabricated using electron beam melting system for dental applications, Journal of Materials Processing Technology 211 (2011) 1400-1408.

24. L.E. Murr, S.M. Gaytan, F. Medina, E. Martinez, D.H. Hernandez, L. Martinez, M.I. Lopez, R.B. Wicker, S. Collins, Effect of build parameters and build geometries on residual microstructures and mechanical properties of Ti-6Al-4V components built by electron beam melting (EBM), Proceedings of 20th Annual International Solid Freeform Fabrication Proceedings, Austin, TX, August 3-5, 2009, pp. 374-397.

25. S. Bontha, N.W. Klingbeil, P.A. Kobryn, H.L. Fraser, Effects of process variables and size-scale on solidification microstructure in beam-based fabrication of bulky 3D structures, Materials Science and Engineering A 513-514 (2009) 311-318.

26. P. Wanjara, M. Brochu, S. Girard, M. Jahazi, Electron beam freeforming on type 321 stainless steel using $\mathrm{BNi}-2$ brazing paste, Materials Science and Technology 21 (2005) 613-618.

27. P. Heinl, A. Rottmair, C. Körner, R.F. Singer, Cellular titanium by selective electron beam melting, Advanced Engineering Materials 9 (2007) 360-364.

28. S.M. Gaytan, L.E. Murr, F. Medina, E. Martinez, M.I. Lopez, R.B. Wicker, Advanced metal powder based manufacturing of complex components by electron beam melting, Materials Technology 24 (2009) 181-190.

29. O. Cansizoglu, O. Harrysson, D. Cormier, H. West, T. Mahale, Properties of Ti-6Al-4V non-stochastic lattice structures fabricated via electron beam melting, Materials Science and Engineering A 492 (2008) 468-474.

30. J. Schwerdtfeger, P. Heinl, R.F. Singer, C. Körner, Selective electron beam melting: a new way to auxetic cellular structures, Proceedings of 20th Annual International Solid Freeform Fabrication Proceedings, Austin, TX, August 3-5, 2009, pp. 724-729.

31. L.E. Murr, S.M. Gaytan, M.I. Lopez, E. Martinez, F. Medina, R.B. Wicker, Metallographic characterization of additive-layer manufactured products by electron beam melting of Ti-6Al-4V powder, Practical Metallography 46 (2009) 442-453.

32. K. Puebla, L.E. Murr, S.M. Gaytan, E. Martinez, F. Medina, R.B. Wicker, Effect of melt scan rate on microstructure and macrostructure for electron beam melting of Ti-6Al-4V, Materials Sciences and Applications 3 (2012) 259-264.

33. N. Hrabe, T. Quinn, Effects of processing on microstructure and mechanical properties of Ti-6Al-4V fabricated using electron beam melting (EBM), Part 1: Distance from build plate and part size, Materials Science \& Engineering A 573 (2013) 264-270.

34. M. Svensson, U. Ackelid, Titanium alloys manufactured with electron beam melting mechanical and chemical properties, Medical Device Materials V-Proceedings of the Materials and 
Processes for Medical Devices Conference, Minneapolis, MN, August 10-12, 2009, pp. 189-194.

35. S.M. Gaytan, L.E. Murr, D.H. Hernandez, E. Martinez, S.A. Quinones, F. Medina, R.B. Wicker, Structure-property-process optimization in the rapid-layer manufacturing of Ti-6A1-4V components by electron beam melting, TMS 2009-138th Annual Meeting and Exhibition, San Francisco, CA, February 15-19, 2009, pp. 363-369.

36. L. Ladani, L. Roy, Mechanical behavior of Ti-6Al-4V manufactured by electron beam additive fabrication, Proceedings of the ASME 2013 International Manufacturing Science and Engineering Conference, Madison, WI, June 10-14, 2013, MSEC 2013-1105.

37. X. Li, C. Wang, W. Zhang, Y. Li, Fabrication and characterization of porous Ti6A14V parts for biomedical applications using electron beam melting process, Materials Letters 63 (2009) 403-405.

38. L.J. Gibson, M.F. Ashby, Cellular solids: structures and properties, Pergamon Press, 1988.

39. P. Heinl, L. Müller, C. Körner, R.F. Singer, F.A. Müller, Cellular Ti-6Al-4V structures with interconnected macro porosity for bone implants fabricated by selective electron beam melting, Acta Biomaterialia 4 (2008) 1536-1544.

40. X. Gong, S.B. Kang, S. Li, J.H. Cho, Enhanced plasticity of twin-roll cast ZK60 magnesium alloy through differential speed rolling, Materials and Design 30 (2009) 3345-3350.

41. X. Gong, H. Li, S.B. Kang, J.H. Cho, S. Li, Microstructure and mechanical properties of twin-roll cast Mg-4.5Al-1.0Zn alloy sheets processed by differential speed rolling, Materials and Design 31 (2010) 1581-1587.

42. J. Karlsson, A. Snis, H. Engqvist, J. Lausmaa, Characterization and comparison of materials produced by electron beam melting (EBM) of two different Ti-6Al-4V powder fractions, Journal of Materials Processing Technology 213 (2013) 2109-2118.

43. W. Liu, L. Li, K. Kochhar, A method for assessing geometrical errors in layered manufacturing. Part 2: Mathematical modeling and numerical evaluation, The International Journal of Advanced Manufacturing Technology 14 (1998) 644-650.

44. A.L. Cooke, J.A. Soons, Variability in the geometric accuracy of additively manufactured test parts, Proceedings of 21st Annual International Solid Freeform Fabrication Symposium, Austin, TX, August 9-11, 2010, pp. 1-12.

45. L.E. Murr, S.M. Gaytan, A. Ceylan, E. Martinez, J.L. Martinez, D.H. Hernandez, B.I. Machado, D.A. Ramirez, F. Medina, S. Collins, R.B. Wicker, Characterization of titanium aluminide alloy components fabricated by additive manufacturing using electron beam melting, Acta Materialia 58 (2010) 1887-1894.

46. S. Sabbadini, O. Tassa, P. Gennaro, U.R. Ackelid, Additive manufacturing of gamma titanium aluminide parts by electron beam melting, 2010 TMS Annual Meeting \& Exhibition-Global Innovations in Manufacturing of Aerospace Materials: The 11th MPMD Global Innovations Symposium, Seattle, WA, February 14-18, 2010, pp. 267-274.
47. L.E. Murr, K.N. Amato, S.J. Li, Y.X. Tian, X.Y. Cheng, S.M. Gaytan, E. Martinez, P.W. Shindo, F. Medina, R.B. Wicker, Microstructure and mechanical properties of open-cellular biomaterials prototypes for total knee replacement implants fabricated by electron beam melting, Journal of the Mechanical Behavior of Biomedical Materials 4 (2011) 1396-1411.

48. S.M. Gaytan, L.E. Murr, E. Martinez, J.L. Martinez, B.I. Machado, D.A. Ramirez, F. Medina, S. Collins, R.B. Wicker, Comparison of microstructures and mechanical properties for solid and mesh cobalt-base alloy prototypes fabricated by electron beam melting, Metallurgical and Materials Transactions A 41 (2010) 3216-3227.

49. S.H. Sun, Y. Koizumi, S. Kurosu, Y.P. Li, H. Matsumoto, A. Chiba, Build direction dependence of microstructure and high-temperature tensile property of Co-Cr-Mo alloy fabricated by electron beam melting, Acta Materialia 64 (2014) 154-168.

50. D.A. Ramirez, L.E. Murr, E. Martinez, D.H. Hernandez, J.L. Martinez, B.I. Machado, F. Medina, P. Frigola, R.B. Wicker, Novel precipitate-microstructural architecture developed in the fabrication of solid copper components by additive manufacturing using electron beam melting, Acta Materialia 59 (2011) 4088-4099.

51. L.E. Murr, E. Martinez, S.M. Gaytan, D.A. Ramirez, B.I. Machado, P.W. Shindo, J.L. Martinez, F. Medina, J. Wooten, D. Ciscel, U. Ackelid, R.B. Wicker, Microstructural architecture, microstructures, and mechanical properties for a nickel-base superalloy fabricated by electron beam melting, Metallurgical and Materials Transactions A 42 (2011) 3491-3508.

52. N. Shen, K. Chou, Thermal modeling of electron beam additive manufacturing process - powder sintering effect, ASME International Manufacturing Science and Engineering Conference, Notre Dame, IN, June 4-8, 2012, MSEC 2012-7253.

53. M. Jamshidinia, F. Kong, R. Kovacevic, The coupled CFD-FEM model of electron beam melting (EBM), ASME District F-Early Career Technical Conference, Birmingham, AL, November 2-3, 2013, pp. 163-171.

54. C. Körner, E. Attar, P. Heinl, Mesoscopic simulation of selective beam melting processes, Journal of Materials Processing Technology 211 (2011) 978-987.

55. S. Price, J. Lydon, K. Cooper, K. Chou, Experimental temperature analysis of powder-based electron-beam additive manufacturing, 24th Annual International Solid Freeform Fabrication Symposium, Austin, TX, August 12-14, 2013, pp. $162-173$.

56. X. Gong, B. Cheng, S. Price, K. Chou, Powder-bed electronbeam-melting additive manufacturing: powder characterization, process simulation and metrology, Early Career Technical Conference, Birmingham, AL, November 2-3, 2013, pp. 55-66.

57. J. Schwerdtfeger, R.F. Singer, C. Körner, In situ flaw detection by IR-imaging during electron beam melting, Rapid Prototyping Journal 18 (2012) 259-263.

Cite this article as: Gong X, Anderson T \& Chou K: Review on powder-based electron beam additive manufacturing technology. Manufacturing Rev. 2014, 1, 2. 